\title{
改进型边缘检测技术在台湾海峡及其周边海域海表 温度锋研究中的应用
}

\author{
䂙青岭 (1)(2)，胡建宇 ${ }^{(1)(2 *}$ \\ (1) 近海海洋环境科学国家重点实验室(厦门大学), 厦门 361005; \\ (2) 厦门大学海洋学系, 厦门 361005 ; \\ (3) 中交第一航务工程勘察设计院有限公司, 天津 300222 \\ * 联系人, E-mail: hujy @xmu.edu.cn
}

收稿日期: 2009-03-27; 接受日期: 2009-10-27

国家自然科学基金项目(批准号: 40576015, 40821063, 40810069004)、国家重点基础研究发展计划(编号: 20097CB411803)资助

\begin{abstract}
摘要 利用基于数学形态学的多尺度、多结构元素、自适应加权的边缘检测技术，对 2002 年 9 月至 2008 年 8 月共 6 年的海表温度(SST)卫星遥感数据进行分析, 得出台湾海峡及其周边 海域上的主要锋面位置及其季节、月变化规律. 检测结果表明, 在研究海区共存在 4 个比较稳 定的海表温度锋: 台湾浅滩锋、浙闽沿岸锋、彰云海脊锋和东海陆坡黑潮锋。锋面强度及范围 呈冬强夏弱的特点. 1 5 月份往往是锋面的活跃期, 7 10月份普遍为锋面消亡期.
\end{abstract}

关键词

海表温度锋

遥感

边缘检测

台湾海峡

黑潮
海洋锋一般指性质明显不同的两种或几种水体 之间的狭长过渡带, 狭义上可定义为水团之间的边界 线 ${ }^{[1]}$. 海表温度锋作为海洋锋的一种常见形式, 对海 洋渔业、海上救助和海洋污染的研究均具有重要意义.

遥感技术的应用和进一步发展, 尤其是遥感数 据在空间和时间分辨率上的提高, 使得利用遥感资 料研究海洋表层的锋面现象变为可能. 而台湾海峡 及其周边海域作为海表温度锋的多发区, 已有多名 学者开始利用实测水文资料以及甚高分辨率辐射计 (AVHRR) 获取的 SST 资料进行研究, 如李立等 ${ }^{[2]}$ 对 台湾海峡南部海域海洋锋的分析, Wang 等 ${ }^{[3]}$ 关于南 海北部海表温度锋的研究, 黄韦艮等 ${ }^{[4]}$ 关于我国台湾 海峡及其邻近海域海表温度锋的卫星遥感观测. 这 些研究基本上确定了台湾海峡及其周边海域海表温 度锋的大致位置, 也注意到了锋面的年、季变化, 但 尚未对锋面的月变化等进行研究.
自边缘检测方法被引入海洋学界后, 海表温度 锋的遥感分析取得了很大进展, 代表性成果有 Hickox 等 ${ }^{[5]}$ 关于中国东海、黄海和渤海的研究, Mavor 等 ${ }^{[6]}$ 关于美国乔治滩的研究, Shimada 等 ${ }^{[7]}$ 关于日本 近岸海域的研究, 以及 Chang 等 ${ }^{[8]}$ 关于冬季台湾海峡 的研究. 上述研究成功地将边缘检测技术引入到提 取海表温度锋的工作中, 这种视觉识别技术的应用 在显著提高工作效率的同时, 也降低了因个体差异 造成的人为误差. 但目前应用的边缘检测技术还存 在普遍缺陷: 无法对实际海洋现象做出精确的数学 描述 ${ }^{[9]}$. 简单的边缘检测方法在研究海洋中的锋面现 象时, 未能建立精确的数学方式来描述海洋特征, 因 此不能很好地解决小尺度锋面与大尺度锋面、噪声之 间的矛盾关系, 往往被迫将研究重点放在大、中尺度 锋面系统中. 故此, 如何引入一种与实际海洋符合良 好的边缘检测技术, 并在去除噪声, 检测大、中尺度

引用格式: Pi Q L, Hu J Y. Analysis of sea surface temperature fronts in the Taiwan Strait and its adjacent area using an advanced edge detection method. Sci China Earth Sci, 2010, doi: 10.1007/s11430-010-3060-x 
锋面和兼顾检测中、小尺度锋面问题上找到平衡点, 是边缘检测技术应用于海洋学领域的一个难点.

为解决上述问题, 本文引入了一种基于数学形 态学的多尺度、多结构元素、自适应加权的边缘检测 方法. 该方法不仅能够检测到诸如黑潮锋这种大尺 度的锋面, 也能同时提取出存在于台湾海峡的中、小 尺度锋面. 文章通过对研究区域 $\left(18^{\circ} \sim 30^{\circ} \mathrm{N}\right.$, $\left.116^{\circ} \sim 128^{\circ} \mathrm{E}\right) 2002 \sim 2008$ 年连续 6 年的 SST 数据进行 分析, 得出了台湾海峡及其周边海域的主要锋面位 置, 并对锋面的季节、月变化特征进行讨论.

研究区域地形及水深见图 1. 图中水深采用 NOAA 发布的 ETOPO2 数据, 单位为 $\mathrm{m}$.

\section{1 资料}

海表温度资料选取日本东北大学大气海洋研究 中心 ${ }^{[10]}$ 提供的日平均 SST 数据, 空间分辨率为 $0.05^{\circ}$. 本文在计算过程中, 首先对东北大学所提供的数据 进行切割, 得到研究海区 $\left(18^{\circ} \sim 30^{\circ} \mathrm{N}, 116^{\circ} \sim 128^{\circ} \mathrm{E}\right)$ 的 逐日 SST 资料. 之后, 删除个别存在数据空白的资料, 并进行必要的数据质控. 经上述处理, 共得到 2037 组可用数据. 而后, 将这些数据绘制成台湾海峡逐日 的 SST 灰度分布图(如图 2 所示), 以便进行边缘检测

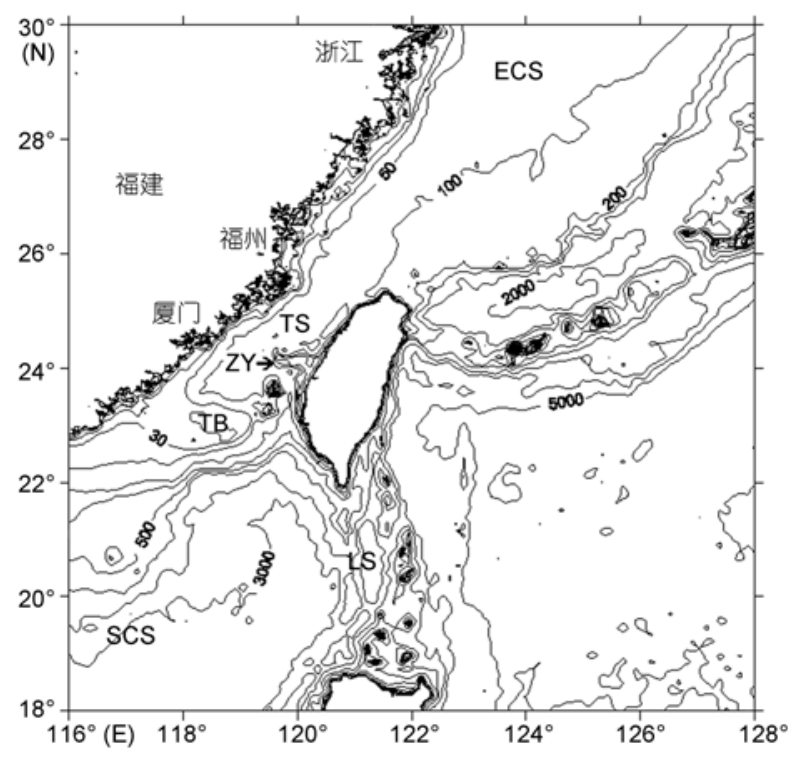

图 1 研究区域地形及水深分布图

图中 SCS, ECS, LS, TS, TB, ZY 分别表示南海、东海、吕宋海峡、 台湾海峡、台湾浅滩、彰云海脊

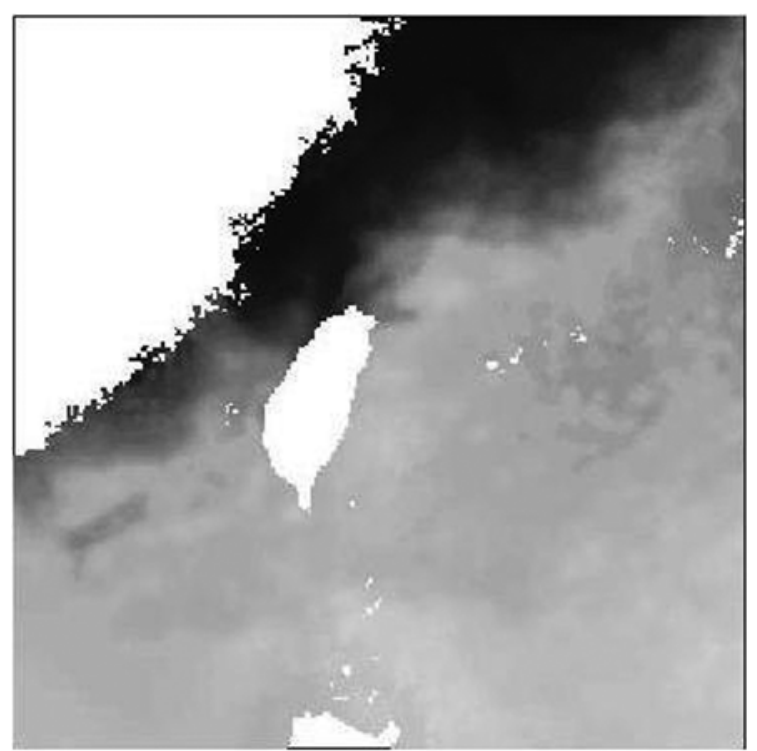

图 22003 年 1 月 28 日研究海区 SST 灰度分布图 研究.

需要指出的是, 该套数据的优点在于融合了 AMSR-E, MODIS, AVHRR 等 SST 遥感资料, 并经过 海表温度反演、云层剔除、质量控制和图像配准, 数 据的连续性很好. 但在资料融合过程中不可避免地 对原数据进行了插值计算, 这势必会造成锋面强度 的减弱. 并且, 由于资料的分辨率相对较低, 使得研 究区域缩小至台湾海峡及其周边海域时, 某些时段 的 SST 图像具有明显的栅格状结构, 本文对个别存 在栅格状的数据进行 $3 \times 3$ 窗平滑, 以避免虚假锋面的 出现. 这些平滑与插值的过程直接导致了所求海表 温度锋的强度较低. 所以, 本文只针对研究海区内存 在的海表温度锋做定性分析.

\section{2 基于数学形态学的灰度图像边缘检测算 法}

数学形态学是一种基于集合论的非线性图像处 理理论, 由法国数学家 G. Matheron 和 J. Serra 于 1964 年提出. 该理论的基本思想是利用一定形态的结构 元素去度量和提取图像中的对应形状，以达到对图 像进行分析和识别的目的. 该方法既有坚实的理论 基础，简洁、朴素、统一的基本思想，又有广泛的实 用价值，严谨的理论系统与简单的基本概念相得益 彰 ${ }^{[11]}$. 


\section{1 数学形态学基本运算}

腐蚀(Erosion)与膨胀 (Dilation) 作为数学形态学 的一级运算, 是其他高级运算的基础. 令原始灰度图 像为 $f(x, y)$, 定义域为 $D_{1}$; 结构元素为 $s(k, l)$, 定义域 为 $D_{2}$, 则 $s$ 对 $f$ 的腐蚀记为 $f \Theta s$, 定义为

$$
f \Theta s=
$$$$
\min \left\{f(x+k, y+l)-s(k, l) \mid(x+k),(y+l) \in D_{1} ;(k, l) \in D_{2}\right\} .
$$

$s$ 对 $f$ 的膨胀记为 $f \oplus s$, 定义为

$$
\begin{aligned}
& f \oplus s= \\
& \max \left\{f(x-k, y-l)+s(k, l) \mid(x-k),(y-l) \in D_{1} ;(k, l) \in D_{2}\right\} .
\end{aligned}
$$

开运算(Open)和闭运算(Close) 是建立在腐蚀与 膨胀运算基础上的二级运算. 开运算为先对图像进 行腐蚀, 后进行膨胀的过程; 闭运算正好相反, 为先 对图像进行膨胀，后进行腐蚀的过程.

结构元素 $s$ 对图像 $f$ 进行开运算记为 $f \circ s$, 定义 为

$$
f \circ s=(f \Theta s) \oplus s .
$$

结构元素 $s$ 对图像 $f$ 进行闭运算记为 $f \bullet s$, 定义为

$$
f \bullet s=(f \oplus s) \Theta s .
$$

\section{2 结构元素}

对于形态学边缘检测而言, 结构元素的选取对 检测结果至关重要. 多尺度形态学边缘检测法, 便是 利用大小不同的结构元素提取图像的边缘特征. 小 尺度结构元素的抗噪能力弱, 但能检测到细节边缘; 大尺度的结构元素抗噪能力强, 但检测到的边缘较 粗 ${ }^{[12,13]}$. 而多结构体的结构元素与单一结构元素相 比, 显然更适于解决 SST 图像中锋面走向的不一致 性问题.

本文首先选取四个方向 $3 \times 3$ 的结构元素(图 3), 该种形状的结构元素经过 Shimada 等 ${ }^{[7]}$ 的检验, 能够 很好地胜任锋面检测的任务. 并且, 通过结构元素的
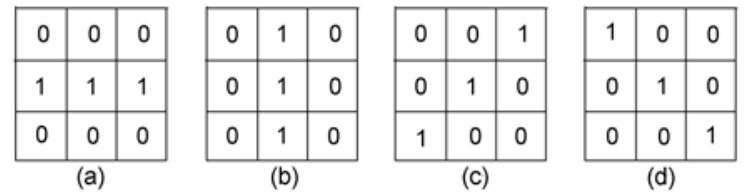

图 3 四个方向 3×3 结构元素示意图 (a) 水平, (b) 坚直, (c) 右倾 $45^{\circ}$, (d) 左倾 $45^{\circ}$
自身膨胀可以得到大尺度的结构元素, 表示如下:

$$
S_{n+1}=S_{n} \oplus S_{n},
$$

式中, $S_{n}$ 表示某一尺度的结构元素, 而 $S_{n+1}$ 为经膨胀 后得到的大尺度结构元素. 经本文试验, 膨胀一次即 可满足研究海区内海表温度锋的检测需求.

\section{3 改进型边缘检测算子}

本文采用连静和王珂 ${ }^{[14]}$ 提出的一种基于数学形 态学的改进型边缘检测算子，简述如下：

抗噪膨胀型算子 $N E M O_{1 m}$ 和抗噪腐蚀型算子 $N E M O_{2 m}$ 分别表示为

$$
\begin{aligned}
& N E M O_{1 m}(x, y)=[(f \circ s) \oplus s](x, y)-[(f \circ s) \bullet s](x, y), \\
& N E M O_{2 m}(x, y)=[(f \bullet s) \circ s](x, y)-[(f \bullet s) \Theta s](x, y) .
\end{aligned}
$$

令检测到的边缘为 $E D$, 则单一尺度结构元素的 边缘可表示为

$$
E D(x, y)=N E M O_{1 m}(x, y)+E_{d e c}(x, y),
$$

而 $E_{d e c}(x, y)=E_{\text {max }}(x, y)-E_{\min }(x, y)$, 其中:

$$
\begin{aligned}
& E_{\text {min }}(x, y)=\min \left\{N M E O_{1 m}, N M E O_{2 m}\right\}, \\
& E_{\max }(x, y)=\max \left\{N M E O_{1 m}, N M E O_{2 m}\right\} .
\end{aligned}
$$

按以上算法得到不同尺度结构元素下的边缘之 后, 还需要对所有尺度下的边缘进行(自适应)加权合 成, 公式如下:

$$
f^{\prime}(x, y)=\sum_{n=1}^{\mathrm{k}} W_{n} E D_{n}(x, y),
$$

式中, $f^{\prime}(x, y)$ 为合成后的边缘图像, 即所求的锋面; $[1, k]$ 为多尺度 $n$ 的取值范围, $k$ 一般取 2 3, 本文取 $k=2 ; W_{n}$ 为各尺度的权重, 通过以下步骤求得：

(1) 求不同尺度下的结构元素对原始图像进行 开闭、闭开滤波后的均值图像:

$$
f_{n}(x, y)=\frac{1}{2}\left[f \bullet s_{n} \bullet s_{n}+f \circ s_{n} \circ s_{n}\right] .
$$

（2）计算不同尺度下的图像方差 $\Delta_{n}=\left|f-f_{n}\right|^{2}$.

(3) 以不同尺度下的图像方差的比例确定权值:

$$
W_{n}=\frac{\Delta_{n}}{\sum_{n=1}^{k} \Delta_{n}} .
$$

通过对 2003 年 1 月 28 日 SST 图像(图 2 所示) 进行上述边缘检测计算，可得到如图 4 所示的边缘图. 可以看出，该方法与依靠肉眼分析的常规方法相比 具有得天独厚的优势：边缘检测方法能够分析出肉 


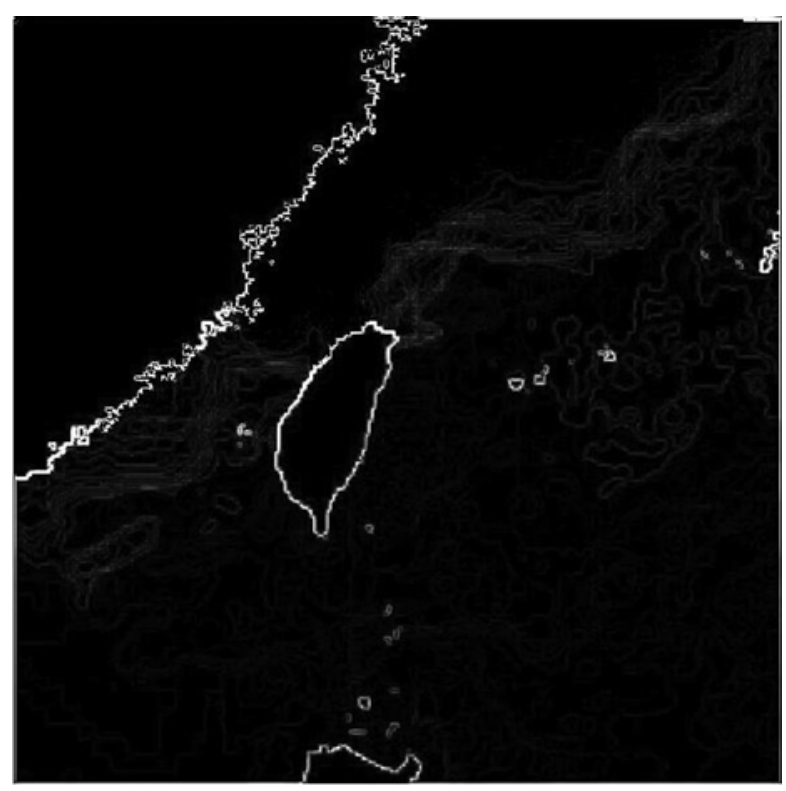

图 42003 年 1 月 28 日研究海区边缘图

眼无法识别的弱边缘, 且能显著降低个体差异造成 的误差. 并且, 该方法兼顾了大尺度边缘及中、小尺 度边缘的检测.

\section{4 锋面梯度计算}

对单张 SST 分布图进行边缘检测计算之后, 可 以得到若干边缘点的位置. 进一步对检测出的边缘 点求温度梯度幅值 (Gradient Magnitude, 简称 $G M$ ), 便可确定锋面强度. $G M$ 通过以下公式求得：

$$
\begin{aligned}
& G M_{x, y}=\sqrt{\left(\frac{\partial T}{\partial x}\right)^{2}+\left(\frac{\partial T}{\partial y}\right)^{2}}, \\
& G M_{m, n}=\sqrt{\left(\frac{\partial T}{\partial m}\right)^{2}+\left(\frac{\partial T}{\partial n}\right)^{2}}, \\
& G M=\max \left(G M_{x, y}, G M_{m, n}\right),
\end{aligned}
$$

式中, $T$ 为海表温度 SST; $x, y$ 分别取东方向和北方向, $m, n$ 分别取北偏东 $45^{\circ}$ 和北偏西 $45^{\circ}$. 具体研究中采 用差分法, 设计一个 $3 \times 3$ 滑动窗口进行计算, 如某一 点 $(i, j)$ 沿 $x, y$ 方向的梯度为

$$
\begin{aligned}
& G M_{i, j}(x, y) \\
= & \sqrt{\left(\frac{S S T_{i+1, j}-S S T_{i-1, j}}{2 d x}\right)^{2}+\left(\frac{S S T_{i, j+1}-S S T_{i, j-1}}{2 d y}\right)^{2}},
\end{aligned}
$$

式中, $d x$ 和 $d y$ 为网格间距.

之后, 再对每天的 $G M$ 进行逐月、季节平均, 即
可分析锋面位置、强度及其变化特征.

\section{3 边缘检测结果分析}

\section{1 黑潮流径海表温度锋}

黑潮对中国近海影响显著, 该影响于南海、东海 和台湾海峡尤甚. 以往很多研究表明: 黑潮在流经吕 宋海峡时，由于失去陆坡的支持变得十分不稳定，易 引起大的蛇行, 并部分入侵南海 ${ }^{[15 \sim 18]}$. 但在本次研 究中(如图 5,6 所示), 黑潮在表层入侵南海时并未产 生较强的海表温度锋, 只在冬、春季节于吕宋岛北部 $\left(19^{\circ} \mathrm{N}, 121.5^{\circ} \mathrm{E}\right)$ 存在些许 $G M$ 较高值的痕迹. 造成吕 宋海峡表层 $G M$ 值过低的可能原因如下: 所用遥感资 料的空间分辨率有限, 并经过一定程度的平滑与插 值, 致使梯度值降低; 并且, 吕宋海峡表层黑潮入侵 并不是稳定的常态现象 ${ }^{[19]}$, 在季平均及月平均状态 下, 锋面强度小于本文规定的梯度阀值 $(G M \geqslant 0.02$ ${ }^{\circ} \mathrm{C} / \mathrm{km}$ ) 也在常理之中. 曾刚 ${ }^{[20]}$ 通过分析实测水文资 料亦指出, 夏季吕宋海峡的海表温度分布均匀, $29^{\circ} \mathrm{C}$ 等温线能够贯穿海峡两侧. 有鉴于此, 本文只针对东 海陆坡区 $\left(25^{\circ} \sim 30^{\circ} \mathrm{N}, 122^{\circ} \sim 124^{\circ} \mathrm{E}\right) 200 \mathrm{~m}$ 等深线处的 黑潮锋(简称东海陆坡黑潮锋, 下同)进行分析, 从而 揭示该锋面的季节及月变化特征.

\subsection{1 东海陆坡黑潮锋的季节变化}

由 6 年季平均温度梯度幅值图(图 5)所示, 在东 海陆架坡折处存在明显的海表温度锋一一东海陆坡 黑潮锋. 该锋面主轴位置相对稳定, 与地形符合良好 (沿 $200 \mathrm{~m}$ 等深线分布). 东海陆坡黑潮锋在春季强度 最大, 且分布范围广, 锋面平均宽度达 $160 \mathrm{~km}, G M$ 最大值位于研究海区东北部, 呈带状分布. 夏季由于 太阳辐射的影响显著增强, 海表温度普遍升高, 升温 作用使得黑潮水与周围水体间温度差减小, 导致夏 季锋面强度降至全年最低, 甚至在 $124^{\circ} \sim 127^{\circ} \mathrm{E}$ 处已 不可见. 秋季该锋面处于成长期, 强度虽明显小于 春、冬季, 但已能辨认出锋面的位置与走向, 在 $124^{\circ} \sim 128^{\circ} \mathrm{E}$ 处已有连续锋面的分布迹象. 冬季锋面强 度仅次于春季, 主轴宽度约 $90 \mathrm{~km}$, 主轴位置与春季 基本一致, 但在台湾岛东北部 $\left(25^{\circ} \sim 27^{\circ} \mathrm{N}, 124^{\circ} \sim 128^{\circ} \mathrm{E}\right)$ 弯曲程度更为剧烈, 该处的锋面强度更大. 上述东海 陆坡黑潮锋的分布形式及其变化特征与汤毓祥 ${ }^{[21]}$ 利 用长周期水文观测资料分析的结果一致，也验证了 

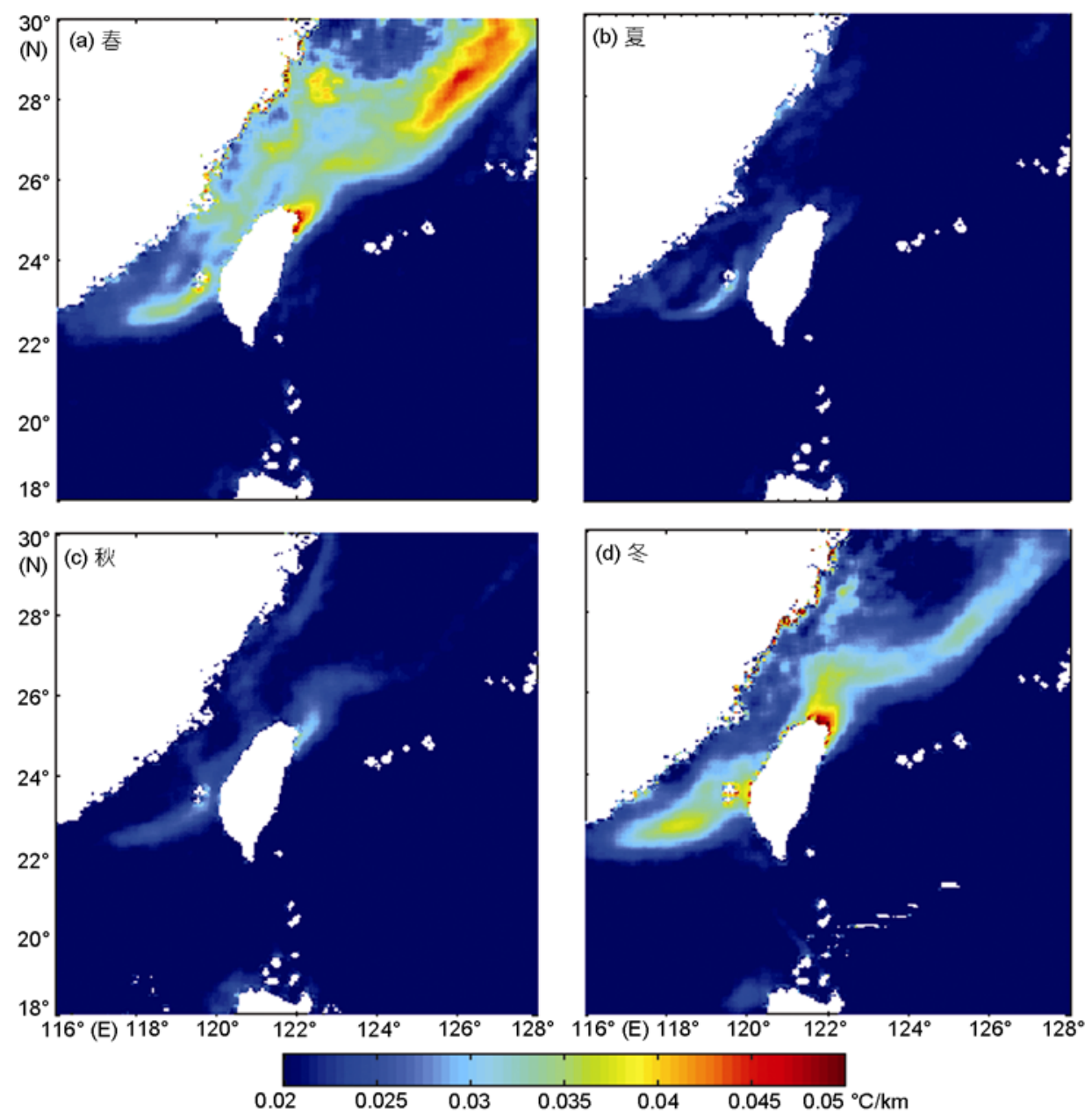

图 5 研究海区 6 年季平均海表温度梯度幅值图

本文所用研究方法的可靠性.

\subsection{2 东海陆坡黑潮锋的月变化}

如图 6 所示, 东海陆坡黑潮锋的强度和形状存在 明显的月变化. 若以 $124^{\circ} \mathrm{E}$ 为界将东海陆坡黑潮锋一 分为二, 可以看出该锋面具有双核结构: 10 月至翌年 2 月, $122^{\circ} \sim 124^{\circ} \mathrm{E}$ 段的锋面强度明显大于 $124 \sim 128^{\circ} \mathrm{E}$ 段; 3 月份二者的强度相当; 而在 4 至 6 月份, $124^{\circ} \sim$ $128^{\circ} \mathrm{E}$ 段的锋面强度更大. 东海陆坡黑潮锋的这种双 核结构恰与其他的研究成果(如 Park 等 ${ }^{[2]}$ 的模型结果) 相一致.

就东海陆坡黑潮锋的月平均状态而言, 处于冬 半年的 1 5 月份锋面最强, 而处于夏半年的 7 10 月 份锋面强度最弱, 甚至不可见. 锋面形状上, 虽然整 体而言东海陆坡黑潮锋的主轴位置变化不大, 但锋
面在台湾岛东北部附近海域 $\left(25.5^{\circ} \mathrm{N}, 123^{\circ} \mathrm{E}\right)$ 的弯曲程 度各月差异较大: 11 月至翌年 3 月份弯曲最为明显, 4 6 月份次之. 造成这种现象的主要原因是地形和季 风: 水深突然变浅, 迫使黑潮在此转向; 而 11 月至翌 年 3 月份属于秋、冬季节，东海盛行干而冷的东北风, 由此产生了西向埃克曼输送及海表的散热降温作 用 ${ }^{[23]}$; 地形与季风相配合, 便造成了东海陆坡黑潮 锋在 11 月至翌年 3 月份在台湾岛东北部附近海域强 度大且弯曲剧烈的现象.

\section{2 台湾海峡海表温度锋}

台湾海峡作为连接东海与南海的狭窄水道, 主 要受以下动力机制影响: 季风、强潮、浙闽沿岸流、 黑潮分支水和南海暖流 ${ }^{[24 ~ 27]}$. 并且, 在台湾浅滩等 海区存在上升流 ${ }^{[28]}$. 复杂的动力机制及多变的地形 

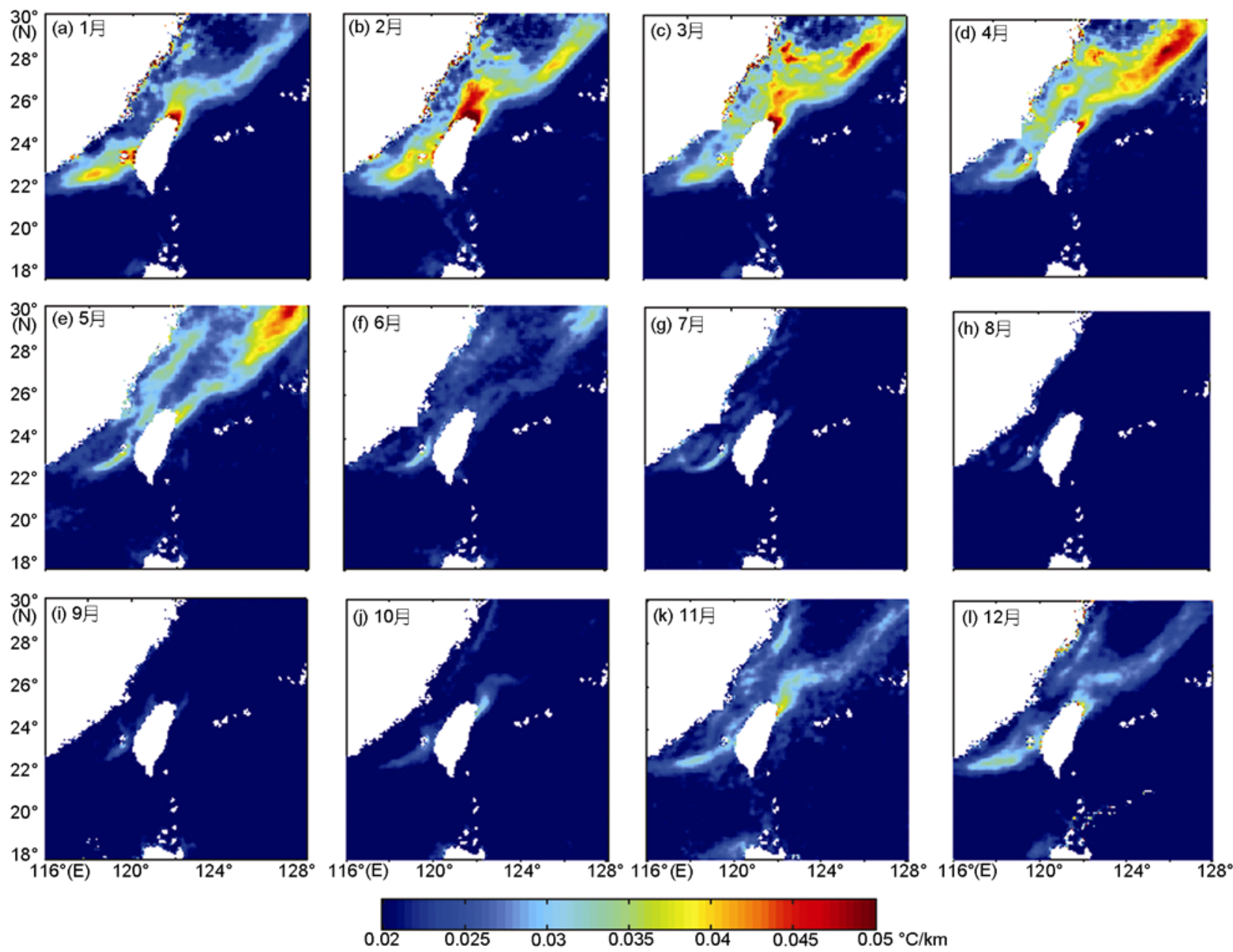

图 6 研究海区 6 年月平均海表温度梯度幅值图

造就了台湾海峡复杂的锋面系统. 为更好地研究台 湾海峡的海表温度锋系统, 特将研究区域缩小至 $21^{\circ} \sim 27^{\circ} \mathrm{N}, 116^{\circ} \sim 122^{\circ} \mathrm{E}$, 该区域的 6 年季平均和月平 均海表温度梯度幅值分布情况分别如图 7,8 所示.

\subsection{1 台湾海峡海表温度锋的季节变化}

图 7(a)为台湾海峡春季的海表温度梯度幅值分 布图. 可以看出, 台湾海峡主要存在 3 个海表温度锋: 台湾浅滩锋、浙闽沿岸锋和彰云海脊锋. 台湾浅滩锋 呈“香蕉形”, 由台湾浅滩延伸至澎湖水道, 长度约 $250 \mathrm{~km}$, 平均宽度 $50 \mathrm{~km}$, 为台湾浅滩海区的上升流 所致 ${ }^{[2,27,28]}$. 浙闽沿岸锋在 $26^{\circ} \mathrm{N}, 121^{\circ} \mathrm{E}$ 附近呈“ “ $\mathrm{S}$ ”形 分布, 西南部弯曲可能是南海暖流沿台湾海峡北上 遭遇较冷的浙闽沿岸水的结果 ${ }^{[24]}$; 而东北部弯曲应 是黑潮分支水从台湾岛东北部入侵的结果 ${ }^{[21,23,29]}$. 同
时, 在台湾岛东北部近岸海域由于黑潮分支水的作 用, 也存在 $G M$ 高值区, 形成了黑潮分支锋. 在彰云 海脊处出现一个呈“C C”形的海表温度锋, 但几乎与浙 闽沿岸锋连成一片。

夏季, 由于台湾海峡其他锋面的衰退, 台湾浅滩 锋的“香蕉形”分布更为突出, 但范围明显减小：长度 降为 $190 \mathrm{~km}$, 平均宽度仅 $30 \mathrm{~km}$. 台湾浅滩锋的强度 与春季相比也明显减弱. 其他锋面均已衰退, 只残存 个别 $G M$ 高值区, 已无法形成连续的稳定锋面.

秋季, 如图 7(c)所示, 海表温度锋的分布形式及 范围与夏季类似. 台湾浅滩的 “香蕉形” 锋面依旧存 在, 长约 $230 \mathrm{~km}$, 平均宽度 $30 \mathrm{~km}$, 范围比夏季略大, 但强度与夏季相比并无太大的变化. 浙闽沿岸海区 依旧未能形成连续的锋面, 但台湾岛东北部的黑潮 分支锋有成长趋势. 

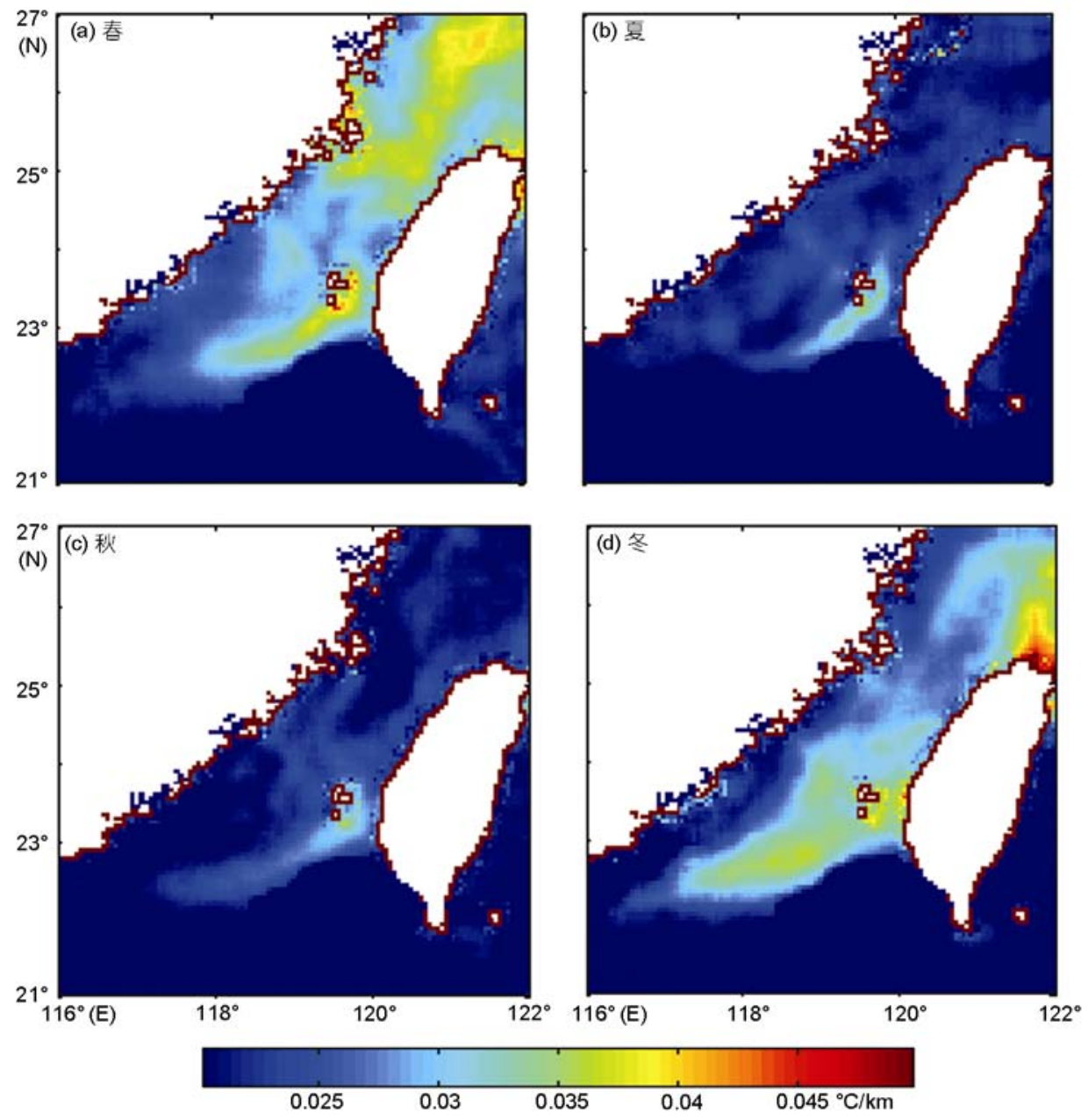

图 7 台湾海峡 6 年季平均海表温度梯度幅值图

冬季, 台湾海峡的主要锋面均已形成, 但强度、 形状与春季并不完全相同. 台湾浅滩锋依旧呈“香蕉 形”, 虽然在强度上与春季基本一致, 但已具有长 300 $\mathrm{km}$ 、平均宽度 $55 \mathrm{~km}$ 的中尺度特征, 几乎与浙闽沿岸 锋及彰云海脊锋连成一片. 在 $26^{\circ} \mathrm{N}, 121^{\circ} \mathrm{E}$ 附近的浙 闽沿岸锋已不再具有“S”形, 强度也不及春季. 此外, 台湾岛东北部的黑潮分支锋显著增强, 成为冬季台 湾海峡强度最大的海表温度锋.

可见, 与东海陆坡黑潮锋的季节变化一致, 台湾 海峡的锋面系统也具有春、冬季节强, 夏、秋季节弱 的特点.

\subsection{2 台湾海峡海表温度锋的月变化}

从图 8 中可以看出, 总体来说, 1 5 月份是台湾 海陝海表温度锋的活跃期, 此时台湾浅滩锋、浙闽沿
岸锋、黑潮分支锋和彰云海脊锋均清晰可见, 且锋面 强度明显大于其他月份. 6 10 月份, 台湾海峡的锋面 系统处于消退期, 甚至在 10 月份, 除台湾浅滩锋之 外的其他锋面形状均已不易分辨. 而 11 12 月份, 各 锋面强度明显增大的同时, 锋面的主要形状也逐渐 形成.

台湾浅滩锋、彰云海脊锋和台湾岛东北部近岸海 域的黑潮分支锋月变化规律基本一致: 2 月份为锋面 系统最为鼎盛的时期, 此时锋面无论是强度还是范 围都处于全年最大值, 黑潮分支锋的强度更是达到 了研究海区内所有锋面强度之最; 自 3 月份起, 彰云 海脊锋和黑潮分支锋开始逐渐衰退, 直至 8 10 月份 达到锋面的消亡期; 11 月份起锋面又开始成长. 与彰 云海脊锋和黑潮分支锋相比, 台湾浅滩锋终年存在, “香蕉形”结构也比较稳定. 

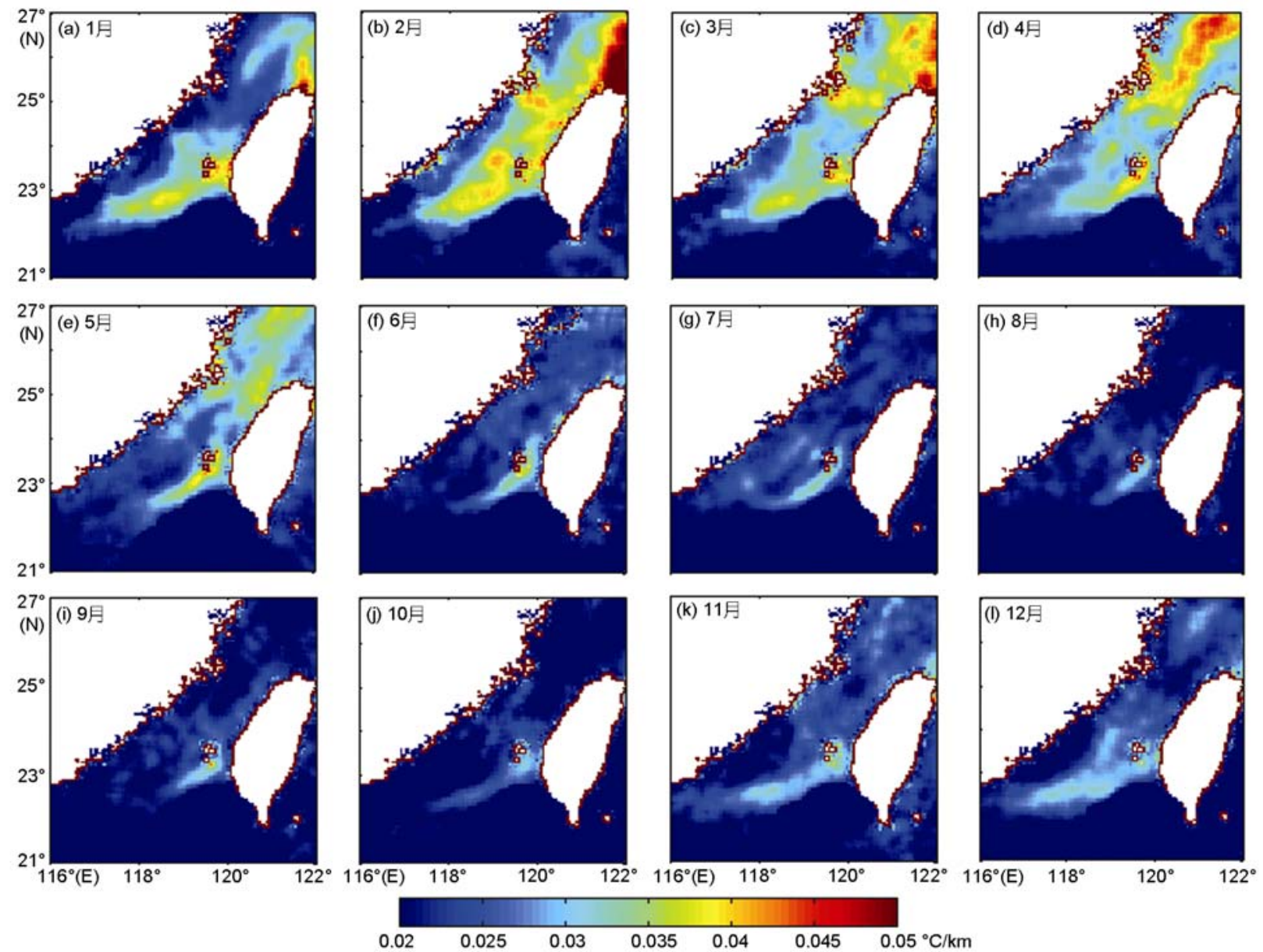

图 8 台湾海峡 6 年月平均海表温度梯度幅值图

与其他锋面类似，浙闽沿岸锋也是自 5 月份开始 衰退, 11 月份开始成长. 但浙闽沿岸锋在 4 月份达到 鼎盛时期, 强度和范围最大, 且具有“ $S$ ”形结构.

\section{4 结论与讨论}

本文通过基于数学形态学的多尺度、多结构元 素、自适应加权的边缘检测方法, 不仅检测出黑潮这 种大、中尺度的锋面系统, 也检测出了台湾浅滩锋、 彰云海脊锋等中、小尺度锋面系统. 经分析, 得出以 下主要结论:

(1) 通过检测, 研究区域内主要存在台湾浅滩 锋、浙闽沿岸锋、彰云海脊锋以及东海陆坡黑潮锋.

（2）台湾浅滩锋具有常年稳定的“香蕉形”结构, 浙闽沿岸锋在春季呈“S”形分布.

(3) 受太阳辐射、季风等影响, 研究区域内锋面
存在明显的季节变化. 研究表明, 该海域冬、春季节 为锋面的活跃期, 锋面强度大、范围广; 夏季锋面最 弱; 秋季普遍为锋面的成长期.

(4) 研究海域内锋面存在明显的月变化. 在研究 区域内, 1 5 月份锋面最为盛行, 强度大且范围广; 6 月份锋面开始逐渐衰退; 11 月份大部分锋面开始成 长.

(5) 东海陆坡黑潮锋的主轴相对稳定, 且在台湾 岛东北部海域常存在弯曲现象. 弯曲程度在冬半年 最为剧烈.

值得一提的是, 本研究采用的 SST 资料在预处 理时加入了平滑与插值, 这势必会造成锋面强度的 减弱. 所以, 本次研究只针对锋面现象进行定性分析, 期待今后可应用于更高分辨率的遥感资料, 以达到 定量分析的效果. 
致谢ＳST 资料由日本东北大学大气海洋研究中心提供, 两位匿名审稿人对本文提出的宝贵意见, 在此一并致谢.

\section{参考文献}

1 冯士筰，李风岐，李少菁. 海洋科学导论. 北京：高等教育出版社, 1999

2 李立, 郭小钢, 吴日升. 台湾海峡南部的海洋锋. 台湾海峡, 2000, 19: 147-156

3 Wang D X, Liu Y, Qi Y Q, et al. Seasonal variability of thermal fronts in the Northern South China Sea from satellite data. Geophys Res Lett, 2001, 28: 3963-3966

4 黄韦艮, 林传兰, 楼琇林, 等. 台湾海峡及其邻近海域海面温度锋的卫星遥感观测. 海洋学报, 2006, 28: 49-55

5 Hickox R, Belkin I, Comillon P, et al. Climatology and seasonal variability of ocean fronts in the East China, Yellow and Bohai Seas from satellite SST data. Geophys Res Lett, 2000, 27: 2945-2948

6 Mavor T P, Bisagni J J. Seasonal variability of sea-surface temperature fronts on Georges Bank. Deep-Sea Res Part II-Trop Stud Oceanogr, 2001, 48: 215-243

7 Shimada T, Sakaida F, Kawamura H, et al. Application of an edge detection method to satellite images for distinguishing sea surface temperature fronts near the Japanese coast. Remote Sens Environ, 2005, 98: 21-34

8 Chang Y, Shimada T, Lee M A, et al. Wintertime sea surface temperature fronts in the Taiwan Strait. Geophys Res Lett, 2006, 33: L23603

9 Krishnakumar N, Sitharama S L, Holyer R, et al. Feature labelling in infrared oceanographic images. Image Vis Comput, 1990, 8: 142-147

10 Sakaida F, Kawamura H, Takahashi S, et al. Research and development of the New Generation Sea Surface Temperature for Open Ocean (NGSST-O) product and its demonstration operation. J Oceanogr, 2009, 65: 859-870

11 崔屹. 图像处理与分析一数学形态学方法及应用. 北京: 科学出版社, 2000

12 Chanda B, Kundu M K, Padamaja Y V. A multi-scale morphologic edge detection. Pattern Recognit, 1998, 31: 1469-1478

13 李卓, 郭立红. 多尺度形态学边缘检测算法. 电子器件, 2006, 29: 821-824

14 连静, 王珂. 多尺度形态学图像边缘检测方法. 计算机工程与应用, 2006, 5: 77-79

15 李燕初, 李立, 林明森, 等. 用 TOPEX/POSEIDON 高度计识别台湾西南海域中尺度强涡. 海洋学报, 2002, 24: 163-170

16 刘增宏, 许建平, 朱伯康. Argos 表面漂流浮标在黑潮区的若干观测结果. 东海海洋, 2004, 22: 2-10

17 李立, 苏纪兰, 许建平. 南海的黑潮分离流环. 热带海洋, 1997, 16: 42-57

18 刘秦玉, 刘倬腾, 郑世培, 等. 黑潮在吕宋海峡的形变及动力机制. 青岛海洋大学学报, 1996, 4: 413一420

19 Yuan D L, Han W Q, Hu D X. Surface Kuroshio path in the Luzon Strait area derived from satellite remote sensing data. J Geophys Res, 2006, 111: C11007

20 曾刚. 巴士海峡水文特征的差异分析. 台湾海峡, 1995, 14: 379-385

21 汤毓祥. 东海黑潮锋的分布特征及其季节变异. 海洋与湖沼, 1996, 27: 436-444

22 Park S, Chu P C. Thermal and haline fronts in the Yellow/East China Seas: Surface and subsurface seasonality comparison. J Oceanogr, 2006, 62: 617-638

23 汤毓祥. 东海黑潮区域性变异的分析. 海洋学报, 1995, 17: 22-29

24 Liang W D, Tang T Y, Yang Y J, et al. Upper-ocean currents around Taiwan. Deep-Sea Res Part II-Trop Stud Oceanogr, 2003, 50: 10851105

25 商少凌, 洪华生, 商少平, 等. 1998 年冬季台湾海峡的暖水入侵及其生态影响. 遥感学报, 2001, 5: 383一 387

26 肖晖, 郭小钢, 吴日升. 台湾海峡水文特征研究概述. 台湾海峡, 2002, 21: 126-138

27 Jan S, Wang J, Chern C S, et al. Seasonal variation of the circulation in the Taiwan Strait. J Mar Syst, 2002, 35: 249-268

28 Hu J Y, Kawamura H, Hong H S, et al. A review of research on the upwelling in the Taiwan Strait. Bull Mar Sci, 2003, 73: 605-628

29 Hsueh Y. The Kuroshio in the East China Sea. J Mar Syst, 2000, 24: 131-139 